\title{
Improved Direct Power Control of Shunt Active Power Filter with Minimum Reactive Power Variation and Minimum Apparent Power Variation Approaches
}

\author{
Tapankumar Trivedi ${ }^{\dagger}$, Rajendrasinh Jadeja* and Praghnesh Bhatt**
}

\begin{abstract}
Direct Power Control technique has become popular in the grid connected Voltage Source Converter (VSC) applications due to its simplicity, direct voltage vector selection and improved dynamic performance. In this paper, a direct method to determine the effect of voltage vector on the instantaneous active and reactive power variations is developed. An alternative Look Up Table is proposed which minimizes the commutations in the converter and results in minimum reactive power variation. The application of suggested table is established for Shunt Active Power Filter (SAPF) application. The Predictive Direct Power Control method, which minimizes apparent power variation, is further investigated to reduce commutations in converters. Both the methods are validated using 2 kVA laboratory prototype of Shunt Active Power Filters (SAPF).
\end{abstract}

Keywords: Direct power control, Synchronous reference frame, Active power filters

\section{Nomenclature}

$v_{p c c} \quad$ Grid voltage vector at point of common coupling

$i_{c} \quad$ Compensating current vector

$s_{i n j} \quad$ Instantaneous complex power injected by SAPF

Complex conjugate of vector

Inverter voltage vector

$\begin{array}{ll}\boldsymbol{v}_{i n v} & \text { Inverter voltage } \\ V_{d c} & \text { DC link voltage }\end{array}$

$\omega$

$V_{m}$

$S_{1}, S_{2}, S_{3}$ Switching states of inverter legs

$R_{f} \quad$ Resistance of smoothening reactor

$L_{f} \quad$ Inductance of smoothening reactor

$\mathfrak{R}() \quad$ real component of complex vector

I) Imaginary component of complex vector

$p_{i n j} \quad$ Instantaneous active power injected by SAPF

$q_{i n j} \quad$ instantaneous reactive power injected by SAPF

$p_{L}, q_{L} \quad$ Instantaneous active and reactive power of load

$v_{p c c, a} v_{p c c, b} v_{p c c, c}$ Instantaneous three phase voltages of grid

$i_{c a}, i_{c b}, i_{c c}$ Instantaneous three phase compensating current of SAPF

$\dagger$ Corresponding Author: EE Department, Marwadi Education Foundation's Group of Institutions, Rajkot., India.

(tapankumar.trivedi@marwadieducation.edu.in)

* EE Department, Marwadi Education Foundation's Group of Institutions, Rajkot., India. (rajendrasinh.jadeja@ marwadieducation.edu.in)

* EE Department, M \& V Patel Dept. of Electrical Engineering, Charotar University of Science and Technology, Changa, India. (pragneshbhatt.ee@charusat.ac.in)

Received: August 22, 2016; Accepted: January 28, 2017 $v_{p c c, d}, v_{p c c, q} \mathrm{~d}$ and $\mathrm{q}$ axis component of grid voltage vector

$i_{c d}, i_{c q} \quad \mathrm{~d}$ and $\mathrm{q}$ axis component of compensating current vector

* $\quad$ Reference quantity

$h_{L x}$ ' $h_{U x} \quad$ Lower and upper limit of hysteresis band

$S_{p}, S_{q} \quad$ Quantized signal of instantaneous active and reactive power errors

$k \quad \mathrm{k}^{\text {th }}$ instant of digital control

$T_{s} \quad$ Sample time of digital controller

\section{Introduction}

Now-a-days, the demand of energy efficient system has forced users as well utility to process the power with Power Electronic Converters. It is expected that Power Electronic Converters will process more than $85 \%$ of the power available to the user. On the contrary, use of Power Electronic Converter raises serious concern over the Power Quality since a power converter controls power in the time domain. The control of power using power electronics is the main source of harmonics and other issues. An SAPF is widely accepted and popular solution for compensation of harmonics.

A Shunt Active Power Filter (SAPF) as shown in Fig. 1 consists of Voltage Source Inverter (VSI), coupling inductors, sensing units and the controller. The performance of such a filter largely depends on the type of compensation scheme applied and control of compensating current. While control of compensating current is obtained using inner current loops, the satisfactory performance of converter is achieved when it is operated at appropriate DC link voltage. In one way, a Pulse Width Modulated Inverter 


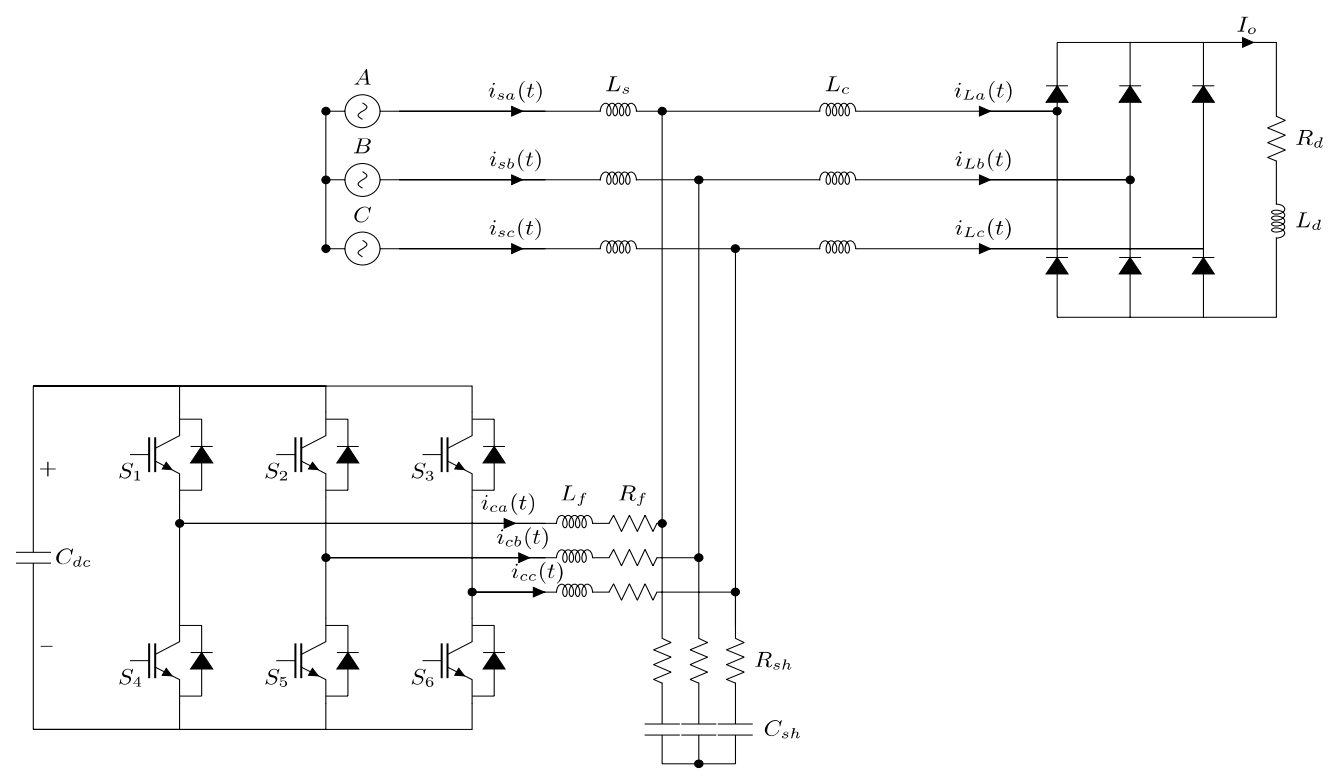

Fig. 1 Power circuit diagram for shunt active power filter

of SAPF may be viewed as a grid-connected converter in which power demands of the grid are slightly different from the conventional grid-connected inverters feeding/ drawing sinusoidal current to/from the grid. Such gridconnected converter applications require fast power control, better dynamic performance, and protection against overcurrent, which can be easily obtained through widely used current control techniques owing to their numerous advantages. The current control methods are classified as linear and non-linear control [1].

In most of the grid-connected converter applications such as PWM Rectifiers, Renewable Energy Interface, DFIGs, and FACTS devices, the aim of the current control technique is to control the amount of power being exchanged in an instantaneous manner [2]. For achieving this objective, the Direct Power Control (DPC) technique was first proposed in [3] for PWM Rectifier application as a dual of Direct Torque Control (DTC) of induction motor drive. In this method, the instantaneous active and reactive powers are controlled in hysteresis manner. Depending upon the magnitude of instantaneous power, appropriate voltage vector, which results in reduction in error between actual power and commanded power, is applied. The method does not require tuning of parameters and at the same time takes advantage of voltage vectors for realizing instantaneous active and reactive powers. In addition to this, the method does not require line voltage measurements and sensors. However, the method suffers from the disadvantages of higher sampling frequency and variable switching frequency.

Based on above work, several methods such as LookUp Table [4, 5], Virtual Flux DPC [6], Model-based DPC [7, 8] and Predictive Control [9] are proposed for achieving objectives of minimum power variation rates, reduced sampling frequency, better dynamic performance and reducing variation in switching frequencies.

The look-up table method has the disadvantage of variable switching frequency whereas Model-based DPC and Predictive Control require more computational efforts. These methods have been mainly applied to grid connected PWM converter application such as PWM Rectifier[3], grid connected DC/AC inverter [10] and DFIGs [11]. However, recently their applications to Active Power Filter have also gained attention. In [12], the authors used only active switching vectors for control of instantaneous active and reactive powers. The switching table is a modification of Eloy-Garcia Table [4]. The method worked well only for sinusoidal supply voltages, and the bands of instantaneous active and reactive powers are varied to reduce commutations. A similar application of Active Front End Converter having capability to mitigate harmonic in the multi-converter system was investigated in [13]. DPC method with High Selectivity Filter (HSF) was implemented in [14] keeping the source conditions into considerations.

All above methods reported in the literature are based on the selection of appropriate converter voltage vector, which can be found after the computations of voltage vector effect in respective sectors using stationary reference frame. These methods fail to determine voltage vectors directly for the given position of grid voltage vector. Any Look Up Table (LUT) based DPC operates in hysteresis manner, hence requires higher sampling frequency. Such look-up table methods confine the selection of voltage vector to a pre-calculated unique voltage vector in table for respective quantized errors. Hence, under given conditions, the possibility of application of any other voltage vector is eliminated. In contrast, to look up table method with unique voltage vector, the predictive direct power control calculates power variation due to all possible vectors 
online and selects the optimum vector based on minimum power variation. The approach results in benefits that are two-fold (a) Voltage vector in given sector is selected and applied such that apparent power variation is minimum. (b) The nearest voltage vectors are selected so that minimum number of commutations occurs.

Based on limitations reported in the literature, the major objectives of the paper are as follows.

- To utilize synchronously rotating reference frame to decide the position of grid voltage vector to minimize power variation rates.

- To propose a method of Predictive Direct Power Control to minimize instantaneous active and reactive power variations with the approach of application of nearest vector which results in reduced number of commutations, requirement of lesser sampling frequency, thus improving the performance of the system.

- The experimental validation of the above proposed objectives.

In view of above objectives, the paper is organized into seven sections. In Section-II, the principle of direct power control based on voltage space phasor is explained. The block diagram of the direct power control as applied to SAPF is shown in Section III. The synchronous reference frame theory applied for Direct Power Control method is presented in section-IV. The concept of minimum reactive power variation to control reference powers employed in SAPF is shown in Section-V whereas Predictive Direct Power Control theory is explained in section-VI.

\section{Principle of Direct Power Control}

For SAPF with point of common coupling voltage $\mathbf{v}_{\text {pec }}$ and compensating current $\mathbf{i}_{\mathbf{c}}$, instantaneous complex power is given by

$$
S_{\text {inj }}=\frac{3}{2} \mathbf{v}_{\text {pcc }} \hat{\mathbf{i}_{\mathbf{c}}}
$$

Differentiating Eq.(1), we get

$$
\frac{d s_{i n j}}{d t}=\frac{3}{2}\left[\mathbf{v}_{\mathbf{p c c}} \frac{d \hat{\mathbf{i}_{\mathbf{c}}}}{d t}+\hat{\hat{\mathbf{i}}_{\mathbf{c}}} \frac{d \mathbf{v}_{\mathbf{p c c}}}{d t}\right]
$$

Differentiation of current is obtained from KVL and is written as,

$$
\frac{d \hat{\mathbf{i}_{\mathbf{c}}}}{d t}=\frac{1}{L_{f}}\left\{\widehat{\mathbf{v}_{\mathbf{i n v}}}-\widehat{\mathbf{v}_{\mathbf{p c c}}}-\widehat{\mathbf{i}_{\mathbf{c}}} R_{f}\right\}
$$

Here, $\mathbf{v}_{\mathbf{i n v}}$ is inverter voltage space phasor and depending

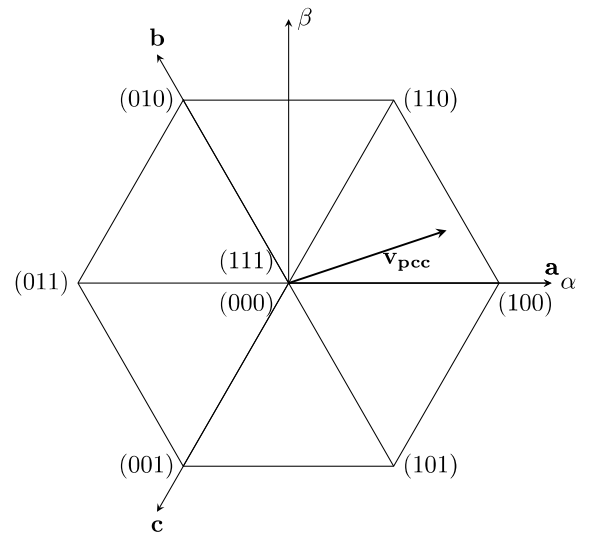

Fig. 2 Space vector diagram for two level inverter

upon switching combinations of switches; it occupies fixed positions in the $\alpha-\beta$ plane of voltage space phasor structure as shown in Fig. 2. At the same time, differentiation of $\mathbf{v}_{\mathbf{p c c}}$ is given by,

$$
\frac{d \mathbf{v}_{\mathbf{p c c}}}{d t}=j \omega \mathbf{v}_{\mathbf{m}} e^{j \omega t}
$$

From Eq. (4) and Eq. (2), variation in power is calculated from,

$$
\frac{d s_{i n j}}{d t}=\frac{3}{2} \frac{1}{L_{f}}\left[\mathbf{v}_{\mathbf{p c c}} \widehat{\mathbf{v}_{\text {inv }}}-\left|\mathbf{v}_{\mathbf{p c c}}\right|^{2}-\frac{R_{f}}{L_{f}} s_{i n j}\right]+j \omega s_{i n j}
$$

Since the equation given in Eq. (5) is processed using digital computers/DSPs, differentiation of apparent power results in power variation whereas time differentiation is replaced by fixed sample time $T_{s}$ that may be generated using timers/external interrupts. The final equation for complex power variation is written as,

$$
\Delta \mathrm{s}_{\mathrm{inj}}=\frac{3}{2} \frac{1}{L_{f}}\left[\mathbf{v}_{\mathbf{p c c}} \widehat{\mathbf{v}_{\text {inv }}}-\left|\mathbf{v}_{\mathbf{p c c}}\right|^{2}-\frac{R_{f}}{L_{f}} s_{i n j}\right] T_{s}+j \omega s_{i n j} T_{s}
$$

The instantaneous active and reactive powers are calculated as,

$$
\begin{aligned}
& \Delta p_{i n j}=\mathfrak{R}\left(\Delta s_{i n j}\right) \\
& \Delta q_{i n j}=\mathfrak{I}\left(\Delta s_{i n j}\right)
\end{aligned}
$$

Substituting values of voltage vector of point of common coupling (PCC) as well as the inverter voltage vector into Eq. (6) results into power variation rates for state vectors in respective sectors. The above method needs computations based on inverter voltage vector and voltage vector of point of common coupling which can be executed using any program, but it fails to provide clear insight into the effect of inverter voltage vector on the present 
condition of PCC vector state.

\section{Direct Power Control of Shunt Active Power Filter}

From the instantaneous power theory, the instantaneous active and reactive powers are defined in terms of average component and oscillating components.

$$
\begin{aligned}
& p_{L}=\overline{p_{L}}+\widetilde{p_{L}} \\
& q_{L}=\overline{q_{L}}+\widetilde{q_{L}}
\end{aligned}
$$

To reduce distortions in the source current, the SAPF must compensate for the oscillating component of the instantaneous powers i.e. $\tilde{p}_{L}$ and $\tilde{q}_{L}$.

These components can be obtained by using either low pass filter (LPF) as shown in Eq. (8) or a high pass filter (HPF) which generates higher frequency components directly. In addition to the oscillating components, the SAPF has to compensate for real power loss. The real power loss $p_{\text {loss }}$ is a measure of losses in the active power filter system. Since these losses are to be fed by DC link capacitor, it results in the reduction of DC link capacitor voltage value. Hence, $p_{\text {loss }}$ can be determined by PI controller in which reference is pre-determined and is compared with actual DC link voltage measured by the voltage sensor. In the case of SAPF, converter will effectively work when DC link voltage value is set to

$$
\geq \frac{2}{m} \sqrt{\frac{2}{3}} V_{L L}
$$

The reference powers are compared with the actual instantaneous active and reactive powers injected by the filter from the equations(9-10)[12],

$$
p_{i n j}=v_{p c c, a} i_{c a}+v_{p c c, b} i_{c b}+v_{p c c, c} i_{c c}
$$

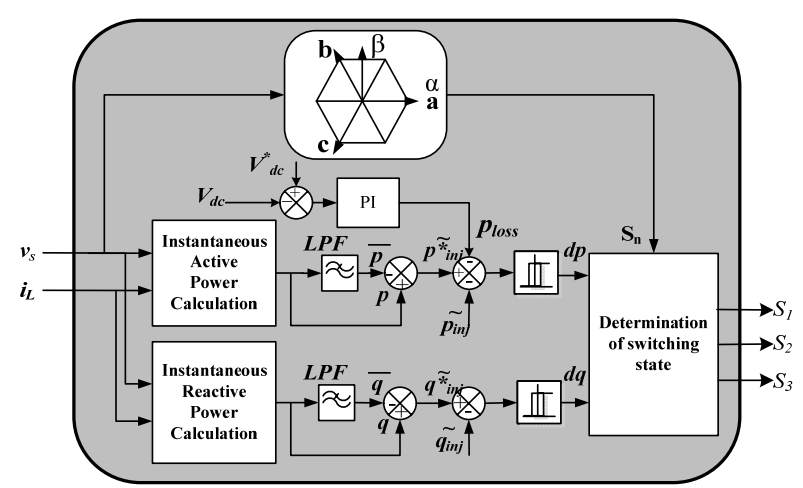

Fig. 3 General block diagram of direct power control for shunt active power filter

$$
q_{i n j}=\frac{1}{\sqrt{3}}\left\{\begin{array}{l}
\left(v_{p c c, b}-v_{p c c, c}\right) i_{c a}+\left(v_{p c c, c}-v_{p c c, a}\right) i_{c b}+ \\
\left(v_{p c c, a}-v_{p c c, b}\right) i_{c c}
\end{array}\right\}
$$

The errors of the active and reactive powers are defined by $d p_{i n j}$ and $d q_{i n j}$ which are decided from,

$$
\left\{\begin{array}{l}
S_{p}=1 \text { if } p_{i n j}^{*}-p_{i n j}<h_{L p} \\
S_{p}=0 \text { if } p_{i n j}^{*}-p_{i n j} \geq h_{U p}
\end{array}\right.
$$

and

$$
\left\{\begin{array}{l}
S_{q}=1 \text { if } q_{i n j}^{*}-q_{i n j}<h_{L q} \\
S_{q}=0 \text { if } q_{i n j}^{*}-q_{i n j} \geq h_{U q}
\end{array}\right.
$$

where $h_{L x}$ and $h_{U x}$ are lower and upper hysteresis band limit for the respective power errors. From the outputs of Eq. (11) and (12), the appropriate voltage vector can be selected from the look-up table which forces power error to approach different combination. From the analysis of instantaneous power variation in respective sectors (illustrated in Section-2), application of voltage vector $\mathbf{V}_{\mathbf{1}}$ in Sector-I implies that the inverter acts as an active power source to the PCC and supplies reactive power. This means that such application of vector will result in an increase of active and reactive powers provided by the converter to the PCC, thus reducing the power error in negative direction. On the contrary, application of vector $\mathbf{V}_{2}$ in Sector-I results in an increase in active power supplied by the inverter, but now it draws reactive power from the PCC, thus reducing power error in positive direction. It is important to note that, zero vector $\mathbf{V}_{\mathbf{0}}$ effectively shorts all the phases; hence, there is no reactive power exchange between inverter and PCC.

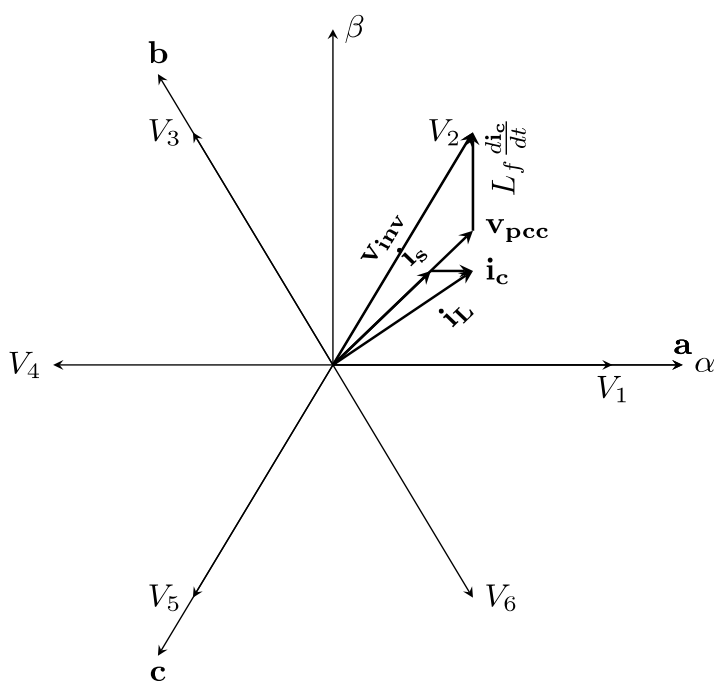

Fig. 4 Phasor diagram of shunt active power filter indicating effect of one vector on compensation 


\section{Synchronous Reference Frame theory for DPC}

The instantaneous active and reactive powers in arbitrary reference frame are given by,

$$
\begin{aligned}
& p_{i n j}=\frac{3}{2}\left(v_{p c c, d} i_{c d}+v_{p c c, q} i_{c q}\right) \\
& q_{i n j}=\frac{3}{2}\left(v_{p c c, q} i_{c d}-v_{p c c, d} i_{c q}\right)
\end{aligned}
$$

Considering reference frame of calculation to be synchronized with PCC voltage vector, the instantaneous active and reactive power variations are obtained by differentiating above equation,

$$
\begin{aligned}
\frac{d p_{i n j}}{d t} & =\frac{3}{2} v_{p c c, d} \frac{d i_{c d}}{d t} \\
\frac{d q_{i n j}}{d t} & =-\frac{3}{2} v_{p c c, d} \frac{d i_{c q}}{d t}
\end{aligned}
$$

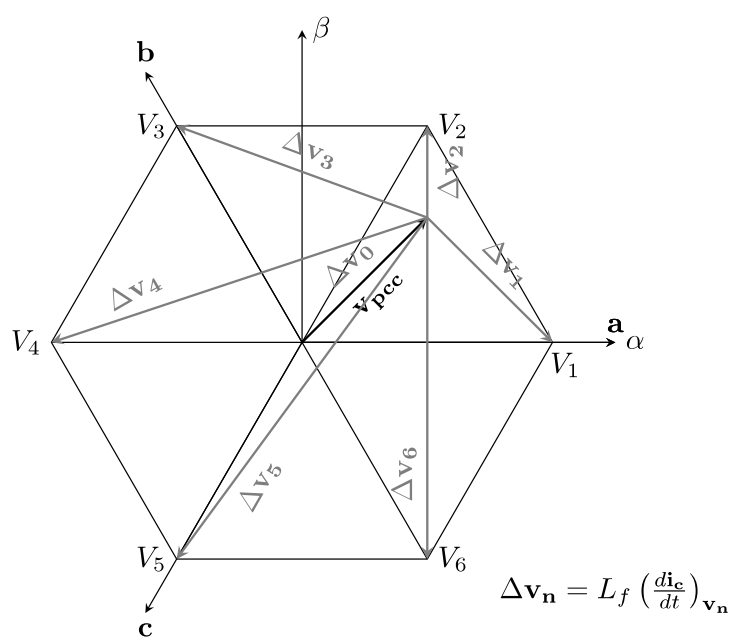

(a)

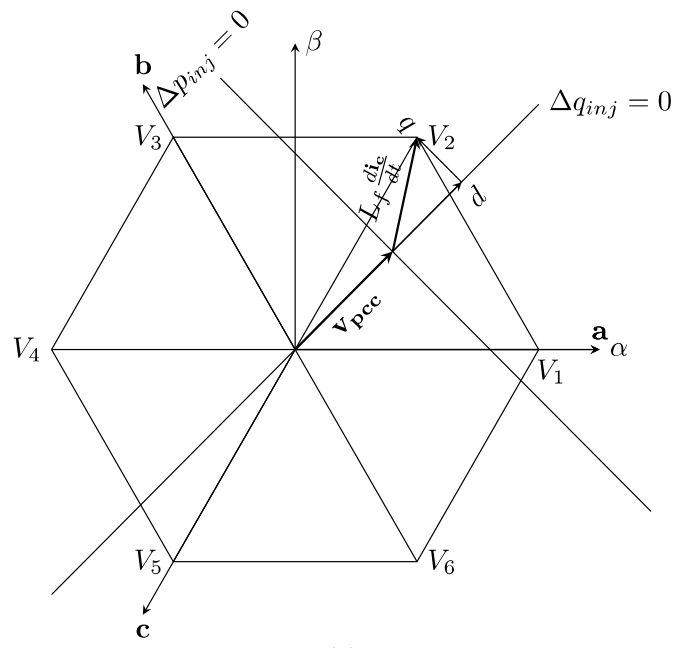

(c)
Assuming voltage drop across the resistor to be negligible, Eq. (3) can be decomposed into

$$
\begin{aligned}
& \frac{d i_{c d}}{d t}=\frac{1}{L_{f}}\left(v_{i n v, d}-v_{p c c, d}-R_{f} i_{c d}\right)+\omega i_{q} \\
& \frac{d i_{c q}}{d t}=\frac{v_{i n v, q}}{L_{f}}-R_{f} i_{c q}-\omega i_{d}
\end{aligned}
$$

Substituting Eq. (15) in Eq. (14) results into

$$
\begin{aligned}
& \frac{d p_{i n j}}{d t}=\frac{3}{2} v_{p c c, d}\left(\frac{v_{i n v, d}-v_{p c c, d}-R_{f} i_{c d}}{L_{f}}\right)- \\
& \frac{3}{2} v_{p c c, d} i_{c d} \frac{R_{f}}{L_{f}}+\frac{3}{2} \omega v_{p c c, d} i_{q} \\
& \frac{d q_{i n j}}{d t}=-\frac{3}{2} \frac{v_{p c c, d} v_{i n v, q}}{L_{f}}+\frac{3}{2} v_{p c c, d} i_{c q} \frac{R_{f}}{L_{f}}+\frac{3}{2} \omega v_{p c c, d} i_{d}
\end{aligned}
$$

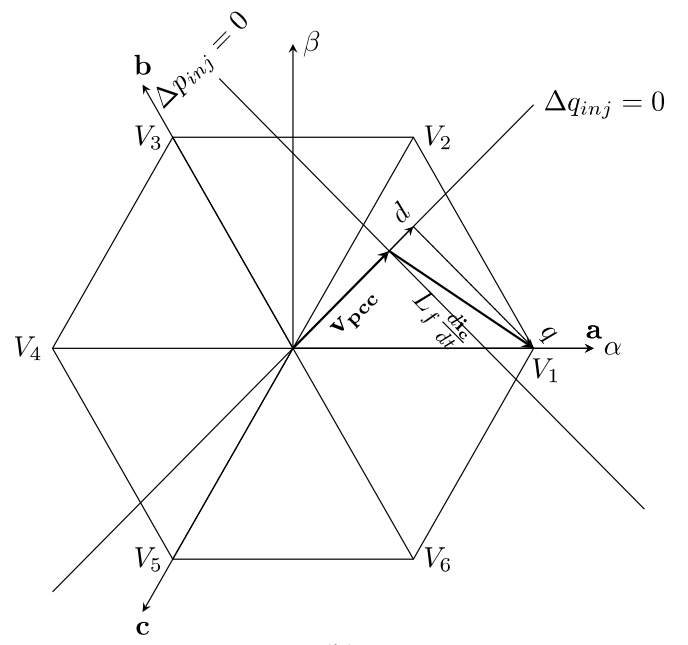

(b)

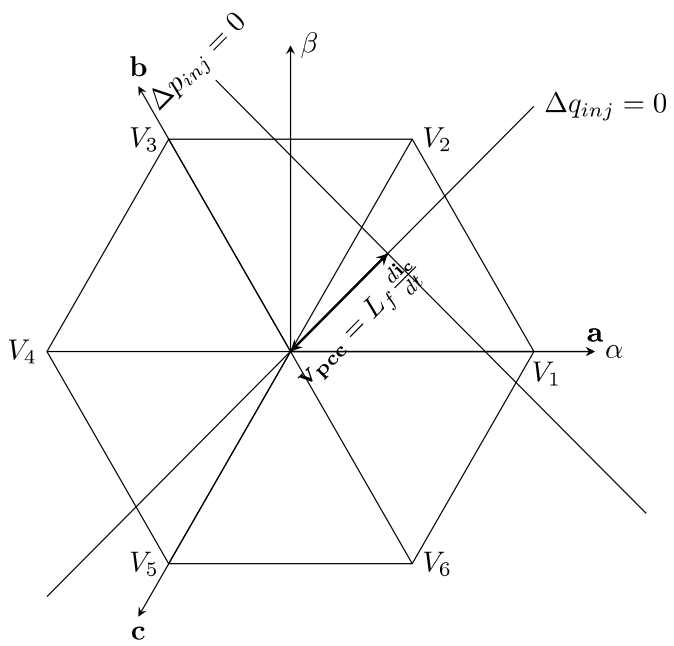

(d)

Fig. 5 Effect of State Vector on power variations: (a) Error voltage vector due to various switching states for sector-I positioning of grid voltage vector; (b) Effect of vector V1 on power variations; (c) Effect of vector V2 on power variations; (d) Effect of zero vector on power variation 
Rewriting Equation in terms of $p_{i n j}$ and $q_{i n j}$

$$
\begin{aligned}
& \frac{d p_{i n j}}{d t}=\frac{3}{2} v_{p c c, d}\left(\frac{v_{p c c, d}-v_{i n v, d}-R_{f} i_{c d}}{L_{f}}\right)-p_{i n j} \frac{R_{f}}{L_{f}} \\
& -\omega q_{i n j} \\
& \frac{d q_{i n j}}{d t}=-\frac{3}{2} \frac{v_{p c c, d} v_{i n v, q}}{L_{f}}-q_{i n j} \frac{R_{f}}{L_{f}}+\omega p_{i n j}
\end{aligned}
$$

From above equations, it can be determined that instantaneous active power variation depends on direct axis component of $d i_{c} / d t$ whereas instantaneous reactive power variation depends on quadrature axis component of $d i_{c} / d t$. These components for given application of vector is shown in Fig. 5. Using this approach, effect of state vector on the variation of power can be determined without involving conventional method of mathematical computations to determine the effect of power variations. These observations are made based on output regulation subspaces mentioned in [8] where it is assumed that power variations are two states of the system. Hence, the equilibrium point is set on the tip of the grid voltage vector (in fact, the point is located on reference voltage vector $v^{*}$ ) and denoted as $(\dot{p}, \dot{q})=(0,0)$.

1. Since direct axis component $d i_{c d} / d t$ is smaller on the right half plane of the origin, power variation is asymmetrical in nature i.e. increase in power due to applied converter voltage vector is less than that of a decrease in power due to applied converter voltage vector in the left half plane.

2. The quadrature axis component $d i_{c q} / d t$ is equal to quadrature axis component of converter voltage vector in the synchronous reference frame. For a given instant, a straight line passing through grid voltage vector bifurcates hexagonal plane into two equal planes. Hence, the projection of either side of the voltage vector on the quadrature axis is same. From this, It can be said that power variation is symmetrical.

3. Since zero vector has zero value of quadrature axis component, the zero or null vectors result in negligible or no variation in instantaneous reactive power which is evident from Eq. (17). In addition, it results in positive variation in instantaneous active power.

The observations made in this section are used for control of active power filter with minimum reactive power variations. The concept of minimum reactive power variation is explained in the following section.

\section{Concept of Minimum Reactive Power Variation}

In above section, it is observed that application of zero vector results in minimum or no reactive power variation. In addition to this, appropriate selection of zero vector in switching sequence results into reduction in number of commutations of the inverter. The effectiveness of the selection of zero vector can be understood well by the illustrative example shown in Fig. 6 where the use of proposed zero vector is compared with existing switching strategy employed in [12] which uses active vectors only.

Starting from zero power variation with $S_{p}>0$ and $S_{q}>0$ in Fig. 6(a), the application of vector $V_{\mathbf{1}}(\mathbf{1 0 0})$ results in smaller positive active power variation whereas reactive power variation is medium for the nearest vectors from $\dot{q}=0$. The magnitude of reactive power for the line is positive for vector $\mathbf{V}_{\mathbf{1}}$ and negative for vector $\mathbf{V}_{\mathbf{2}}$. Since power variation for reactive power components is larger compared to active power variation in nearest vector approach, the instantaneous reactive power error reaches lower band first, hence switching state that results in positive active power variation and negative reactive power variation should be selected, i.e. $\mathbf{V}_{\mathbf{2}}(\mathbf{1 1 0})$ for $S_{p}>0$ and $S_{q}<0$.

At this instant active power variation (error), still continue to increase and hits its lower band. To satisfy the

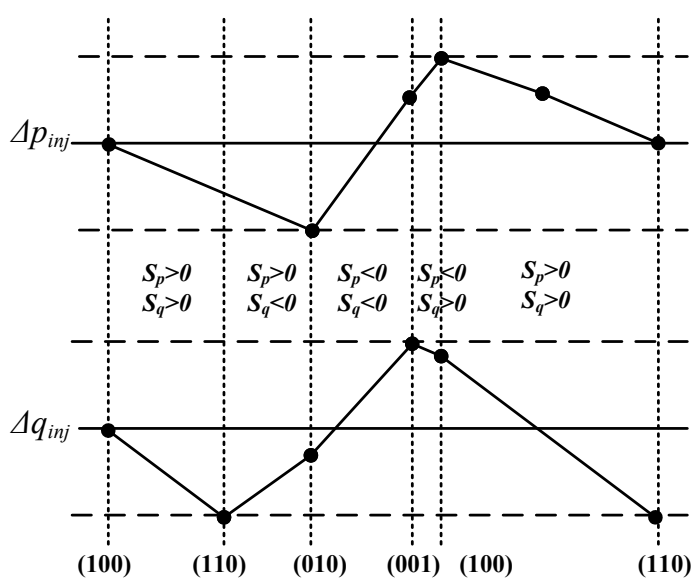

(a)

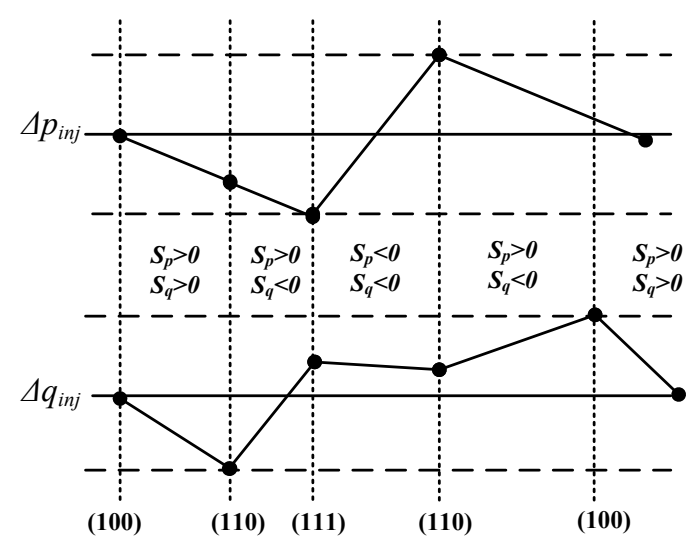

(b)

Fig. 6 Variations in instantaneous power error with applied vector (a) Switching strategy based on active vector selection (b) switching strategy based on minimum reactive power variation 
Table 1. Switching state selection in voltage space phasor structure for minimum reactive power variation

\begin{tabular}{c|c|c|c|c|c|c|c}
\hline $\mathrm{S}_{\mathrm{p}}$ & $\mathrm{S}_{\mathrm{q}}$ & $\Theta_{1}$ & $\Theta_{2}$ & $\Theta_{3}$ & $\Theta_{4}$ & $\Theta_{5}$ & $\Theta_{6}$ \\
\hline 1 & 1 & 100 & 110 & 010 & 011 & 001 & 101 \\
\cline { 2 - 8 } 1 & 0 & 110 & 010 & 011 & 001 & 101 & 100 \\
\hline 0 & 1 & 000 & 111 & 000 & 111 & 000 & 111 \\
\cline { 2 - 8 } 0 & 0 & 111 & 000 & 111 & 000 & 111 & 000 \\
\hline
\end{tabular}

condition for $S_{p}<0$ and $S_{q}<0$, multiple active vectors $\mathbf{V}_{3}(\mathbf{0 1 0}), \mathbf{V}_{\mathbf{4}}(\mathbf{0 1 1})$ or $\mathbf{V}_{\mathbf{0}}(\mathbf{0 0 0}$ or 111) can be selected. However, application of any of the above active vector may lead to following two issues:

1. Commutation of multiple switches at a time

2. The decrease in reactive power which further leads to the selection of another active vector

A modified switching strategy is developed for the application of active power filter without employing space vector modulation strategy. Although the switching strategy is validated for SAPF, the concept can also be extended to other grid-connected converter applications. As can be seen from Fig. 6 (b), the zero vector results in zero or minimum reactive power variation, hence only active power changes for the time being. To reduce commutations, let us assume that applied active vector is $\mathrm{V}_{2}(\mathbf{1 1 0})$, and conditions are $\mathrm{S}_{\mathrm{p}}<0$ and $\mathrm{S}_{\mathrm{q}}<0$, then the suitable vector is $\mathrm{V}_{7}$ (111) as it results in minimum no. of commutations. Further, when conditions changes to $\mathrm{S}_{\mathrm{p}}<0$ and $\mathrm{S}_{\mathrm{q}}>0$, the vector applied is $\mathrm{V}_{\mathbf{0}} \mathbf{( 0 0 0 )}$ resulting in minimum no. of commutations. Based on this, the Table 1 is prepared for nearest vector strategy in various sectors.

\section{Predictive Direct Power Control of Active Power Filter}

This section proposes a predictive direct power control method for SAPF. As mentioned earlier, in computers and digital controllers, the differential equation is converted to difference equations with $T_{s}$ sample time. The Eq. (3) is re-written as

$$
\mathbf{i}_{\mathbf{c}}(k+1)=\left[1-\frac{R_{f} T_{s}}{L_{f}}\right] \mathbf{i}_{\mathbf{c}}(k)+\frac{T_{s}}{L_{f}}\left[\mathbf{v}_{\mathbf{p c c}}(k)-\mathbf{v}_{\text {inv }}(k)\right]
$$

It is clear from Eq. (18) that the compensating current vector can be predicted easily for any application of inverter voltage vector if model parameters and value of current at the $k^{\text {th }}$ instant are known. For the case where sample time is significant as compared to the fundamental period, the voltage at the $(k+1)^{\text {th }}$ instant is given by Eq. (20).

$$
\mathbf{v}_{\mathbf{p c c}}(k+1)=\mathbf{v}_{\mathbf{p c c}}(k)\left(1+j \omega T_{s}\right)
$$

Since instantaneous voltages and currents of all phases are directly available from the measurement units, instantaneous active and reactive powers at $(k+1)^{\text {th }}$ instant can easily be calculated from Eq. (9) and Eq. (10).

The necessary conditions to ascertain minimum apparent power variation so as to decide optimal inverter voltage vector are defined as follow:

Let us consider grid voltage vector and current for the apparent power calculation. The apparent power variation for fixed sample time is given by,

$$
\begin{aligned}
& \mathrm{s}_{\text {inj }}(k+1)=\mathrm{s}_{\text {inj }}(k)\left(1+j \omega T_{s}\right)\left(1-\frac{R_{f} T_{s}}{L_{f}}\right)+\ldots \\
& \frac{3}{2} \frac{\left(1+j \omega T_{s}\right) T_{s}}{L_{f}}\left[\left|\mathbf{v}_{\text {pcc }}\right|^{2}-\mathbf{v}_{\mathbf{p c c}} \widehat{\mathbf{v}_{\text {inv }}}\right]
\end{aligned}
$$

As the terms,

$$
\left(1+j \omega T_{s}\right) \approx 1 \text { and }\left(1-\frac{R_{f} T_{s}}{L_{f}}\right) \approx 1
$$

The equation can be approximated as,

$$
\mathrm{s}_{\mathrm{inj}}(k+1)=\mathrm{s}_{\mathrm{inj}}(k)+\frac{T_{s}}{L_{f}}\left[\left|\mathbf{v}_{\mathbf{p c c}}\right|^{2}-\mathbf{v}_{\mathbf{p c c}} \widehat{\mathbf{v}_{\text {inv }}}\right]
$$

The Eq. (21) resembles to initial definition of apparent power variation derived in Section-2. For minimum apparent power variation, the inverter voltage vector should be selected such that it satisfies,

$$
\begin{aligned}
& \Delta \mathrm{s}_{\text {inj }}=\mathrm{s}_{\text {inj }}(k+1)-\mathrm{s}_{\text {inj }}(k) \\
& \Delta \mathrm{s}_{\text {inj }}=\frac{T_{s}}{L_{f}}\left[\left|\mathbf{v}_{\text {pcc }}\right|^{2}-\mathbf{v}_{\mathbf{p c c}} \widehat{\mathbf{v}_{\text {inv }}}\right] \approx 0
\end{aligned}
$$

Resulting in the condition of

$$
\widehat{\mathbf{v}_{\mathbf{i n v}}} \approx \frac{\left|\mathbf{v}_{\mathbf{p c c}}\right|^{2}}{\mathbf{v}_{\mathbf{p c c}}}=V_{m} e^{-j \omega t} \Leftrightarrow \mathbf{v}_{\mathrm{inv}} \approx V_{m} e^{j \omega t}
$$

In practice, the inverter voltage vector can never attain an exact value of grid voltage vector (except at sector crossing). Hence, the vector that results in minimum power variation should be selected. This can be achieved with the use of any optimization technique. However, it has been found that least square optimization results into minimum online computation efforts. The method is used for the optimal vector selection as given in Eq. (25).

$$
\left|\Delta \mathrm{s}_{\mathrm{inj}}\right|^{2}=\left|p_{i n j}^{*}-p_{i n j}\right|^{2}+\left|q_{i n j}^{*}-q_{i n j}\right|^{2} \approx 0
$$

While applying such vector to the converter in real time, 
the effect of delay should be considered. Therefore, vectors to be applied at $(k+2)^{\text {th }}$ instant are calculated in advance and applied for a $k^{\text {th }}$ instant.

\section{Experimental Results and Discussions}

The method discussed in the paper is validated using a 2 kVA laboratory prototype. The prototype is developed using SKM100GB12T4 power devices which are driven by SKYPER32R driver core. A three phase variac is adopted as grid supply in order to reduce the voltage level of the prototype. The three phase load currents and compensating

Table 2. System parameters for experimental prototype

\begin{tabular}{c|c|c}
\hline Sr.No. & Parameters & Value \\
\hline 1 & Source Line Voltage & $125 \mathrm{~V}$ \\
\hline 2 & Load Resistance & $50 \Omega$ \\
& Load Inductance & $10 \mathrm{mH}$ \\
\hline 3 & Smoothening Reactor & $8.2 \mathrm{mH}$ \\
\hline \multirow{2}{*}{4} & Ripple Filter: & $25 \mu \mathrm{F}$ \\
& Capacitance & $10 \Omega$ \\
\hline 5 & Resistor & $2350 \mu \mathrm{F}, 900 \mathrm{~V}$ \\
\hline 6 & DC link Capacitor & $300 \mathrm{~V}$ \\
\hline
\end{tabular}

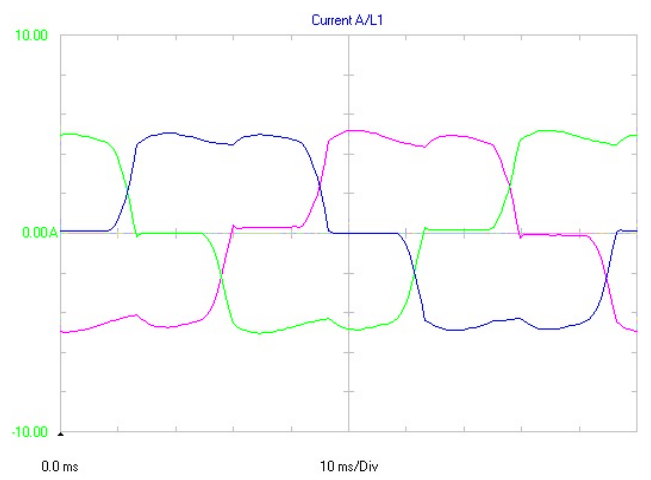

(a) currents are sensed using LA-55P whereas source voltage and DC link voltage are detected using LV20-P voltage transducer. These LEM make Hall Effect transducers are configured for resolution of $667 \mathrm{mV} / \mathrm{A}$ and $21 \mathrm{mV} / \mathrm{V}$ for current sensors and voltage sensors respectively. The direct power control algorithm is implemented using RT-LAB OP4500 Real Time Development board which has Core-i7 processors for algorithm calculations. These processors communicate with Kintex-7 FPGA board in order to read from $\mathrm{ADC}$, write to DAC and control PWM channels for inverter operation. The time-critical events are captured using Yokogawa DLM2024 Mixed Signals Oscilloscope whereas power quality indices are obtained using Fluke 430B Power Quality Analyser. The sampling frequency of the real time algorithm is set to $66 \mathrm{kHz}$.

A diode-bridge rectifier with RL load is considered as a non-linear load which is connected to a variac. The inverter is connected to a point of common coupling through the smoothening inductance of $8.2 \mathrm{mH}$.

To suppress switching ripples due to Voltage Source Inverter, capacitive filter with a damping resistor is connected across the point of common coupling. The parameters of the entire system are tabulated in the load current has a non-linear profile, with lower order harmonics $5^{\text {th }}$ and $7^{\text {th }}$ dominating with the values of $22.4 \%$ and $11.0 \%$

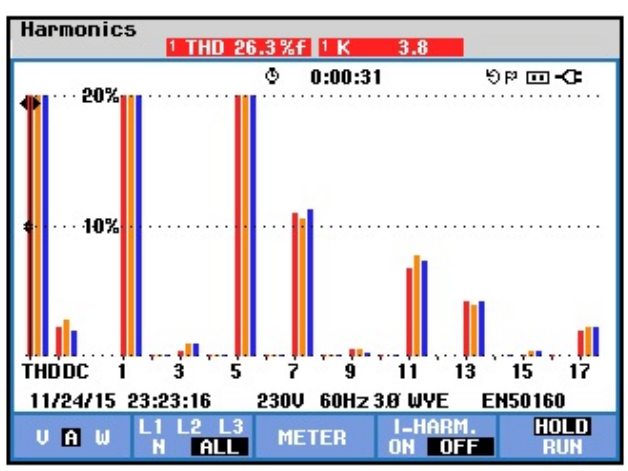

(b)

Fig. 7 (a) Load current for all three phases (b) THD of three phase load current

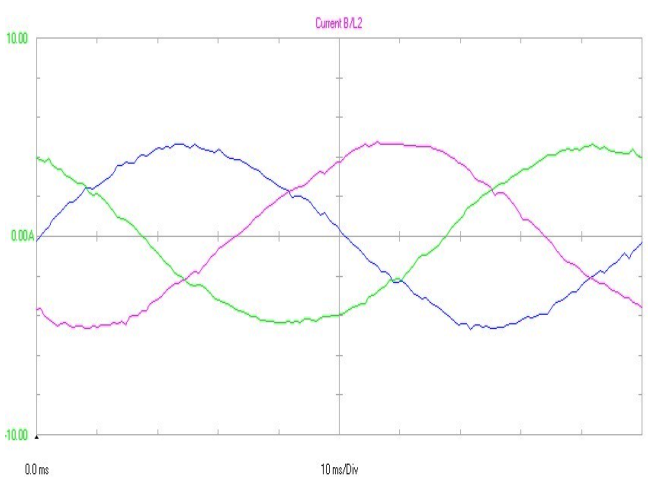

(a)

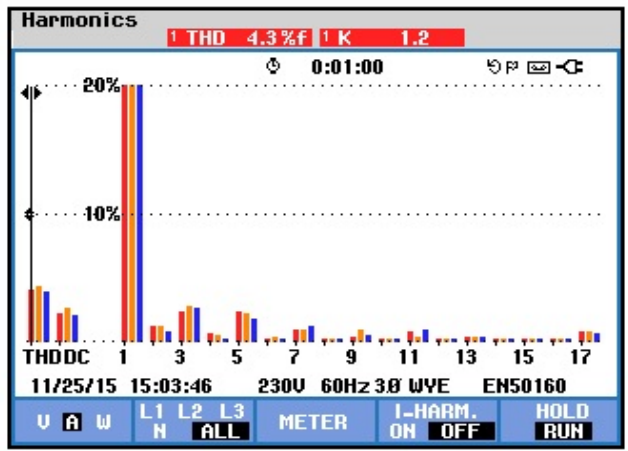

(b)

Fig. 8 Source currents after compensation for conventional Direct Power Control method (a) Three phase source currents (b) THD of three phase source current 
respectively. The overall THD of the system is $26.3 \%$ which is well above acceptable limits.

\subsection{Direct power control with conventional active vectors only}

The SAPF is first tested with the approach mentioned in [12] where only active vectors are selected. As depicted in Fig. 8, the system exhibits satisfactory performance for the

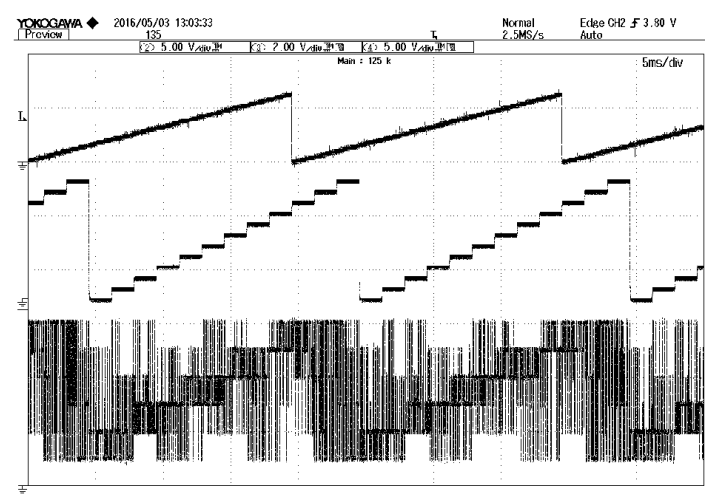

Fig. 9 Grid angular information, Sector selection, voltage vector selection for conventional Direct Power Control method, Ch-1: Grid Angle $(0-2 \pi)$, Ch-2: Sector information $\left(\Theta_{1}-\Theta_{12}\right)$, Ch-3: Voltage Vector Selection $\left(\mathrm{V}_{0}-\mathrm{V}_{6}\right)$

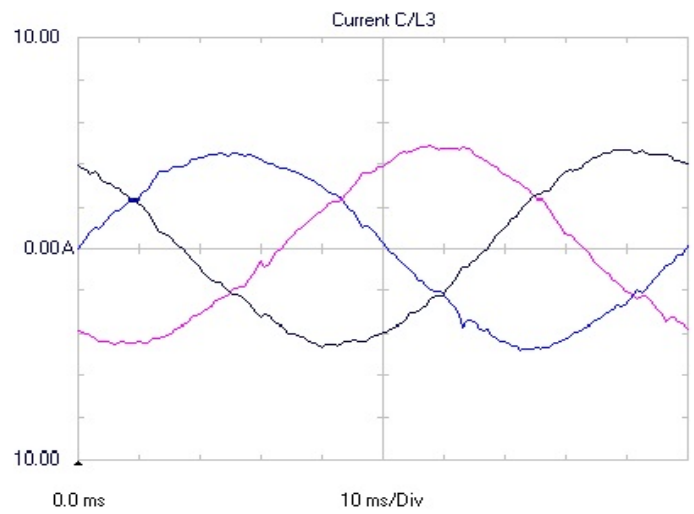

(a)

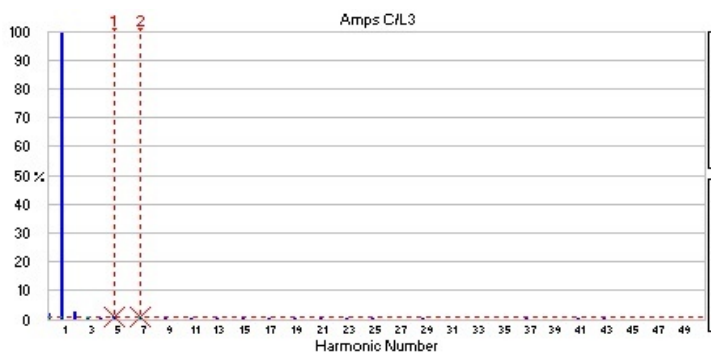

(b)

Fig. 10 Source currents after compensation for Direct Power Control method with minimum reactive power variation approach (a) Three phase source currents (b) THD of three phase source current
SAPF application where THD of source current is reduced to $4.3 \%$. Due to the selection of farthest vectors, switching of the inverter increases active power error. At the same time, it involves multiple commutations. Such a selection of vectors, for given grid angle and sector, is given in Fig. 9. Based on the look-up table, two nearest vectors and two farthest vectors are selected for given power error signals. As a result, the average switching frequency of $7.6 \mathrm{kHz}$ is achieved.

\subsection{Direct power control with minimum reactive power variation approach}

The experimental system is tested with revised Look-Up Table method mentioned in Section-V. It is evident that the unity power factor operation of the overall system is maintained while compensating harmonics of the load as can be seen in Fig. 10. Also, source current has THD of 4.1\% which follows IEEE 519-1992 recommendations.

However, average switching frequency calculation of Mixed Signal Oscilloscope for one fundamental period suggests that the average switching frequency of the inverter is reduced to $6.8 \mathrm{kHz}$ which is much less than the conventional method with active vectors.

Obviously, this is due to the introduction of zero vectors at appropriate place, and minimization of reactive power error. For the proposed method, selection of voltage vector is portrayed in Fig. 12.

The voltage vector selection along with instantaneous active and reactive power errors are captured to verify minimization of reactive power error. The expanded view in Fig. 13 suggests that whenever an active voltage vector is applied, instantaneous reactive power error has a finite slope which it maintains as long as the same voltage vector is used. Whenever a zero vector is used, the error does not

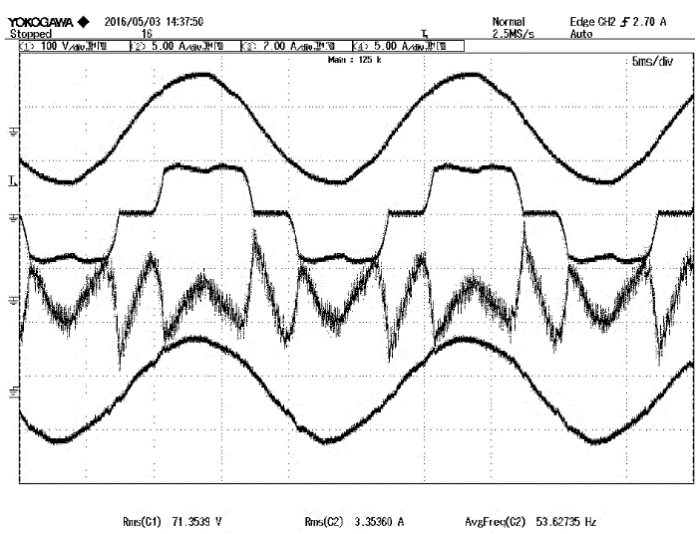

Fig. 11 Source Voltage, Load Current, Compensating Current and Source Current for Direct Power Control with minimum reactive power variation approach, Ch-1: Source Voltage [X-axis: $5 \mathrm{~ms} / \mathrm{div}$, Y-axis: $100 \mathrm{~V} / \mathrm{div}], \mathrm{Ch}-2$ : Load Current [Y-axis: 5A/div], Ch3: Compensating Current [Y-axis: 2 A/div], Ch-4: Source Current [Y-axis: 5 A/div] 
change much, and hence selection of next voltage vector relies on the active power error signal.

\subsection{Direct power control with predictive direct power control method}

The predictive DPC method which aims at minimum apparent power variation is developed in the MATLAB environment. A quick sort algorithm is programmed to find out minimum apparent power error possible and the index of algorithm is used to select the vector. The application of vector minimizes power variation, which is evident from Fig. 17 while maintaining the adequate compensation performance. With this, the average switching frequency of $6.5 \mathrm{kHz}$ is obtained. Although variation of switching frequency is large in the scheme, error of the power is

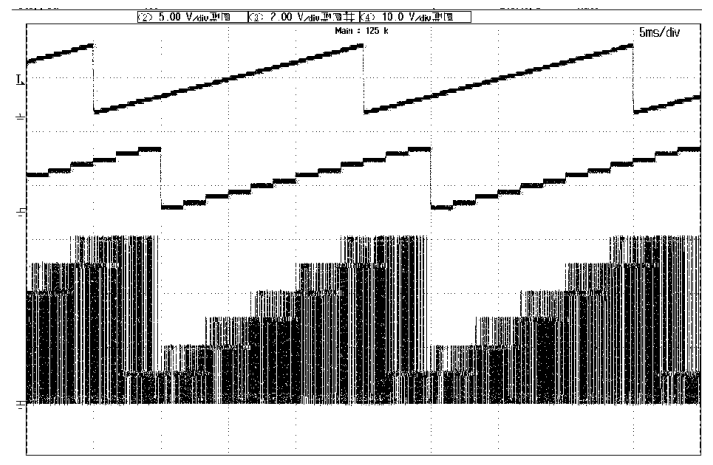

Fig. 12 Grid angular information, Sector selection, voltage vector selection for Direct Power Control with minimum reactive power variation approach, $\mathrm{Ch}$ 1: Grid Angle $(0-2 \pi)$ [X-axis: $5 \mathrm{~ms} /$ div, Y-axis: 5 $\mathrm{rad} / \mathrm{div}]$, Ch-2: Sector information $\left(\Theta_{1}-\Theta_{12}\right)$ [Yaxis: 5 sect/div], Ch-3: Voltage Vector Selection $\left(\mathrm{V}_{0}-\mathrm{V}_{6}\right)$ [Y-axis: 2 vect/div]

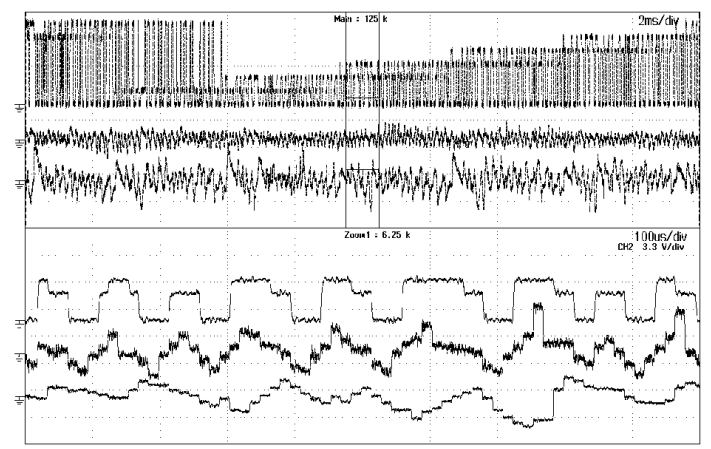

Fig. 13 Voltage Vector Selection, Instantaneous Active and Reactive Power Errors for Direct Power Control with minimum reactive power variation approach - Window-1: Normal View [X-axis:2 ms/div] Window-2: Zoom View [X-axis:100 $\mu \mathrm{s} / \mathrm{div}]$ of Ch1: voltage vector, Ch-2: instantaneous active power error (100W/div) and Ch-3: instantaneous reactive power error (200 VAR/div) maintained well within the limits

Fig. 18 portrays the instantaneous active and reactive power variations on $p-q$ axis which acclaims that the power

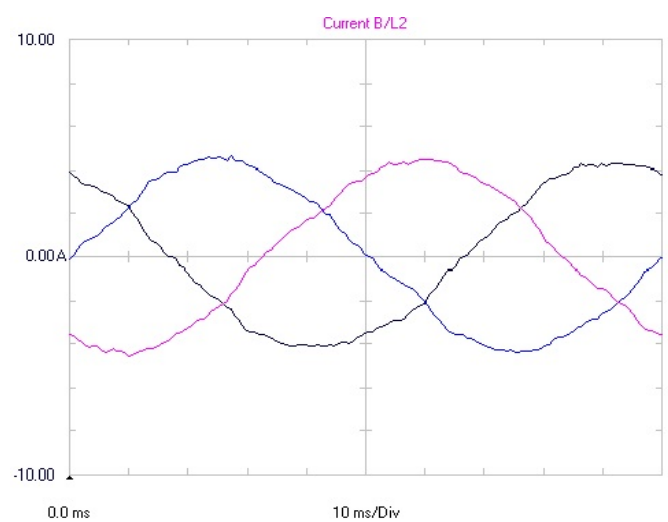

(a)

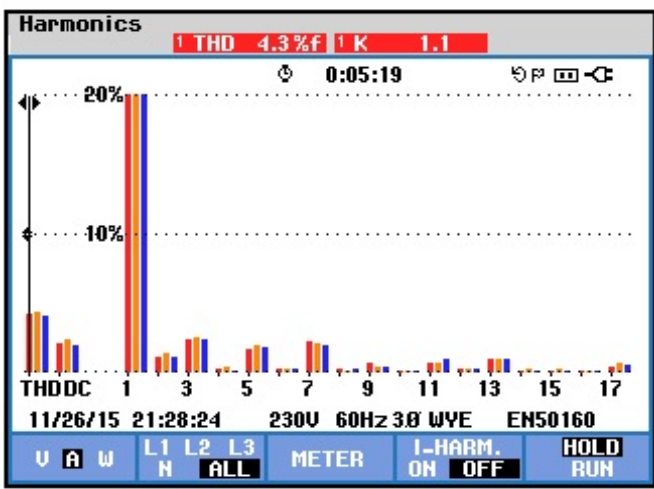

(b)

Fig. 14 Source currents after compensation for Direct Power Control method with minimum apparent power variation approach; (a) Three phase source currents; (b) THD of three phase source current

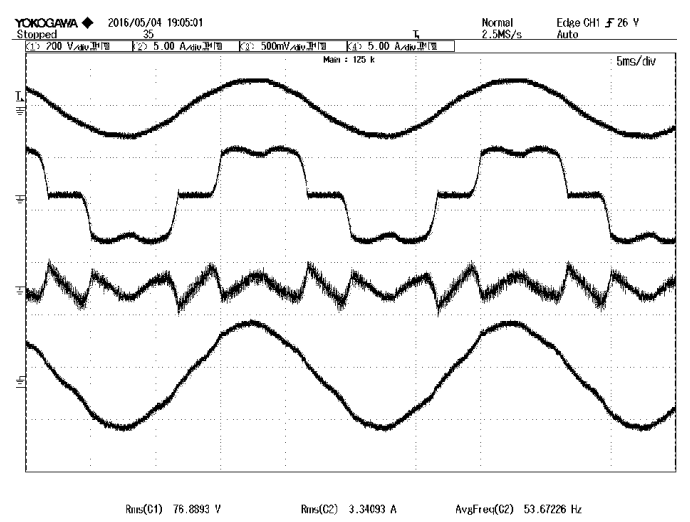

Fig. 15 Source voltage, load current, compensating current and source current for the minimum apparent power variation approach, $\mathrm{Ch}-1$ : Source voltage [X-axis: 5ms/div, Y-axis: $100 \mathrm{~V} / \mathrm{div}$ ], Ch-2: Load current [Y-axis: 5A/div], Ch3: Compensating current [Y-axis: 5 A/div], Ch-4: Source current [Yaxis: $5 \mathrm{~A} / \mathrm{div}$ ] 


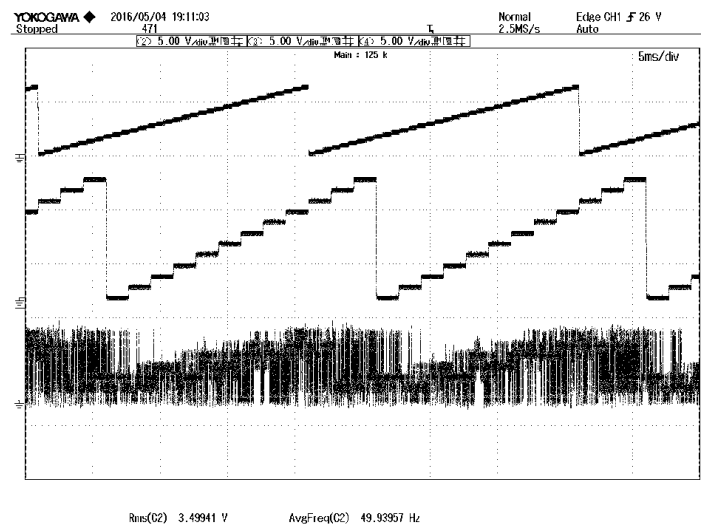

Fig. 16 Grid angular information, Sector selection, voltage vector selection for Direct Power Control with minimum apparent power variation approach, Ch1: Grid Angle $(0-2 \pi)$ [X-axis: $5 \mathrm{~ms} /$ div, Y-axis: 5 $\mathrm{rad} / \mathrm{div}]$, Ch-2: Sector information $\left(\Theta_{1}-\Theta_{12}\right)[\mathrm{X}-$ axis: $5 \mathrm{~ms} / \mathrm{div}, \mathrm{Y}$-axis: 5 sect/div], Ch-3: Voltage Vector Selection $\left(\mathrm{V}_{0}-\mathrm{V}_{6}\right)$ [X-axis: $5 \mathrm{~ms} / \mathrm{div}$, Y-axis: $5 \mathrm{vect} / \mathrm{div}]$

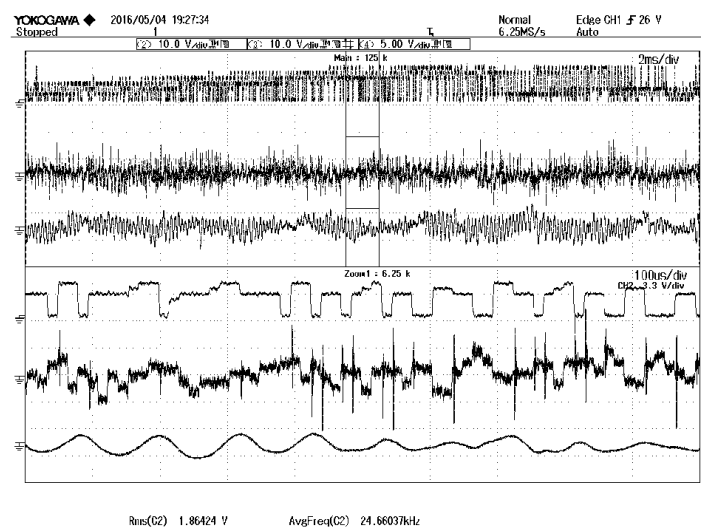

Fig. 17 Voltage Vector Selection, Instantaneous Active and Reactive Power Errors for Direct Power Control with minimum reactive power variation approach - Window-1: Normal View [X-axis:2 ms/div] Window-2: Zoom View [X-axis:100 $\mu \mathrm{s} / \mathrm{div}]$ of Ch1: voltage vector, $\mathrm{Ch}-2$ : instantaneous active power error $(100 \mathrm{~W} / \mathrm{div})$ and $\mathrm{Ch}-3$ : Instantaneous reactive power error $(200 \mathrm{VAR} / \mathrm{div})$

variation is very much contained in the contour around the center point. In the case of look-up table based method, these variations often violate its set limits, especially during the sector crossing.

It is worth noting that all above methods show satisfactory performance as a compensating device. Such a comparison of all the method for given performance parameters are shown in Table 3 However, the approach of minimized reactive power variation and apparent power variation are useful for the applications where THD of the system is large. The application of these methods for such systems still demands investigation.
Table 3. Comparison of Proposed Direct Power Control method of Shunt Active Power Filter

\begin{tabular}{c|c|c|c}
\hline & $\begin{array}{c}\text { Conventional } \\
\text { method with active } \\
\text { vectors }\end{array}$ & $\begin{array}{c}\text { Proposed } \\
\text { look-up } \\
\text { table }\end{array}$ & $\begin{array}{c}\text { Predictive } \\
\text { DPC }\end{array}$ \\
\hline THD of source current & $4.3 \%$ & $4.1 \%$ & $4.3 \%$ \\
\hline Active power variation & Large & Medium & Medium \\
\hline Reactive power variation & Medium & Small & Small \\
\hline $\begin{array}{c}\text { Average switching } \\
\text { frequency }\end{array}$ & $7.6 \mathrm{kHz}$ & $6.8 \mathrm{kHz}$ & $6.5 \mathrm{kHz}$ \\
\hline $\begin{array}{c}\text { Variation in switching } \\
\text { frequency }\end{array}$ & Small $(6.5-8.5 \mathrm{kHz})$ & $\begin{array}{c}\text { Small } \\
(6-8 \mathrm{kHz})\end{array}$ & $\begin{array}{c}\text { Large } \\
(5.5-9 \mathrm{kHz})\end{array}$ \\
\hline
\end{tabular}

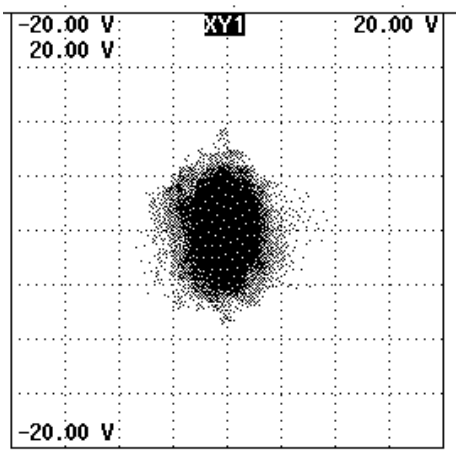

Fig. 18 Instantaneous active and reactive power errors on p-q axis: X-axis: $5 \mathrm{~W} / \mathrm{div}$ Y-axis: $5 \mathrm{VAR} / \mathrm{div}$

\section{Conclusion}

In this paper, the effect of inverter voltage vector on the instantaneous power error for grid-connected converter application is explained using synchronous reference frame theory. The voltage vector that results in active power error and reactive power error can be directly determined from the synchronous reference frame theory based on current vector position and vector to be applied. A look-up table based on adjacent voltage vector in voltage space phasor structure is developed. This look-up table is applied to SAPF application, which suggests that number of commutations of the converters are reduced. It is also shown that using adjacent voltage vector results in minimum reactive power variations and improved performance. The predictive direct power control method is applied to minimize apparent power variation. The method selects optimal voltage vector based on least square optimization technique. The use of Predictive DPC method results in reduced numbers of commutations, optimal voltage vector selection without determination of position of vector in the particular sector

\section{Acknowledgement}

The authors acknowledge financial support by Marwadi Education Foundation's Group of Institutions during execution of the project. 


\section{References}

[1] P. K. Marian and L. Malesani, "Current Control Techniques for Three-Phase Voltage-Source PWM Converters: A Survey," IEEE Transactions on Industrial Electronics, vol. 45, pp. 691-703, 1998.

[2] T. Trivedi, R. Jadeja, and P. Bhatt, "A Review on Direct Power Control for Applications to Grid Connected PWM Converters," Engineering, Technology \& Applied Science Research, vol. 5, pp. 841849, 2015.

[3] T. Noguchi, H. Tomiki, S. Kondo, and I. Takahashi, "Direct Power Control of PWM Converter Without Power Source Voltage Senesors," IEEE Transaction on Power Electronics, vol. 34, pp. 473-479, 1998.

[4] J. Alonso, M. Joaquin, E. Garcia, and C. Arnaltes, "Table Based Direct Power Control- A Critical Review for Microgrid Applications," IEEE Transactions on Power Electronics, vol. 25, pp. 2949-2961, 2010.

[5] Z. Xu and J.-X. Zhao, "A New Direct Power Control Strategy for NPC Three-Level Voltage Source Rectifiers Using a Novel Vector Influence Table Method," JOURNAL OF POWER ELECTRONICS, vol. 15, pp. 106-115, 2015.

[6] M. Malinowski, M. P. Kazmierkowski, S. Hansen, F. Blaabjerg, and G. D. Marques, "Virtual-Flux Based Direct Power Control of Three-Phase PWM Rectifiers," IEEE Transaction on Industrial Applications, vol. 37, pp. 1019-1027, 2001.

[7] Sergio Vazquez, J. A. Sanchez, J. M. Carrasco, J. I. Leon, and E. Galvan, "A Model-Based Direct Power Control for Three-Phase Power Converters," IEEE Transactions on Industrial Electronics, vol. 55, pp. 1647-1657, 2008.

[8] Gerardo Escobar, A. M. Stankovic, J. M. Carrasco, E. Galvan, and R. Ortega, "Analysis and Design of Direct Power Control (DPC) for a Three Phase Synchronous Rectifier via Output Regulation Subspaces," IEEE Transactions on Power Electronics, vol. 18(3), pp. 823-830, 2003.

[9] Sergio Aurtenechea Larrinaga, M. A. Rodriguez, V. Estanis, Oyarbide Apraiz, and J. R. Torrealday, "Predictive Control Strategy for DC-AC Converters Based on Direct Power Control," IEEE Transactions on Industrial Electronics, vol. 54, pp. 1261-1271, 2007.

[10] H. Jiabing and Z. Q. Zhu, "Investigation on Switching Patterns of Direct Power Control Strategies for Grid-Connected DC-AC Converters Based on Power Variation Rates," IEEE Transactions on Power Electronics, vol. 26, pp. 3582-3598, 2011.

[11] D. Zhi and L. Xu, "Direct Power Control of DFIG With Constant Switching Frequency and Improved Transient Performance," IEEE Transactions on Energy Conversion, vol. 22(1), pp. 110-118, 2007.

[12] G. J. Bruce S. Chen, "Direct Power Control of Active
Filters with Averaged Switching Frequency Regulation," IEEE Transaction on Power Electronics, vol. 23, pp. 2729-2737, 2008.

[13] M. Cichowlas, M. Malinowski, M. P. Kazmierkowski, D. L. Sobczuk, P. Rodríguez, and P. Josep, “Active Filtering Function of Three-Phase PWM Boost Rectifier Under Different Line Voltage Conditions," IEEE Transactions on Industrial Electronics, vol. 52, pp. 410-419, 2005.

[14] Nadhir Mesbahia, A. Ouaria, D. Ould, A. T. Djamahc, and A. Omeiri, "Direct Power Control of Shunt Active Filter using High Selectivity Filter(HSF) under Distorted or Unbalanced Conditions," Electric Power Systems Research, vol. 108, pp. 113-123, 2014.

\section{Appendix-I}

For the system with line voltage $V_{p h}=125 \mathrm{~V}$ and load mentioned in the table, the source side current has value of $I_{d}=5 \mathrm{~A}$. Considering the switching losses of IGBT for design of shunt active power filter, the required rating is,

$$
\begin{aligned}
& S_{A P F}=\sqrt{3} V_{L L} I_{L h} \\
& S_{A P F}=\sqrt{3} \times 125 \times 0.265 \times 5 \\
& S_{A P F}=\sqrt{3} \times 125 \times 0.265 \times 5
\end{aligned}
$$

Hence, the rating for propsed test case is calculated as 286 VA. The hyteresis band for the given rating is decided as $\pm 7 \%$ of the total rating i.e. $\pm 20 \mathrm{~W}$ and \pm 20 VAR

Considering maximum instantaneous active power variation occuring on the application zero vector, the minimum inductor value is given by,

$$
L_{f}=\frac{3 V_{p c c}^{2} T_{s}}{2 \Delta p_{i n j}}
$$

For, PCC voltage of $V_{p c c}=72 \mathrm{~V}$, sample time $T_{s}=15 \mu \mathrm{s}$ and $\Delta p_{i n j}=20 \mathrm{~W}$, the minimum value of $L_{f}=5.8 \mathrm{mH}$ is obtained. As the selection of this value will result into frequent crossing of boundaries for non-linear controller, a value of $L_{f}=8.2 \mathrm{mH}$ is selected.

The DC link capacitor value is based on dynamic change in the system where $25 \%$ change in the system voltage is allowed. Hence,

$$
C_{d c}=\frac{2\left(2 \times S_{A P F}-S_{A P F} / 2\right) n T_{f}}{\left(1.125 V_{d c}\right)^{2}-\left(0.875 V_{d c}\right)^{2}}
$$

Where $n$ is no. of cycles within which DC link must be restored and $T_{f}$ is the time period of fundamental cycle. The value of DC link capacitor is,

$$
C_{d c}=1906 \mu F
$$


Since the nearest value available is $2350 \mu \mathrm{F}$, it is chosen in the present system.

The AC side capacitor filter must be tuned at half the average switching frequency (which in this case is 3500 $\mathrm{Hz})$ to suppress ripples in the source side voltage. If reactance at the switching frequency is assumed as $2 \Omega$, the value of capacitor is obtaied as $C_{f}=22 \mu \mathrm{F}$. Similarly, the value of damping resistor is chosen as $10 \Omega$.

The external control loop i.e. voltage control loop is tuned with $K_{p}=45$ and $K_{i}=18$ and validated under different condition in order to obtain satisfactory steady state as well as dynamic performance.

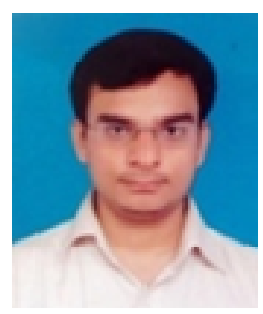

Tapankumar Trivedi is Asstt. Proessor at Marwadi Education Foundation's Group of Institutions. He completed M. Tech. from Indian Institute of Technology (IIT), Roorkee. He is currently pursuing Ph.D. at Charotar University of Science and Technology. His areas of interest include Power Quality Improvement devices, control of power electronic converters, and Multilevel Inverter-fed IM Drives.

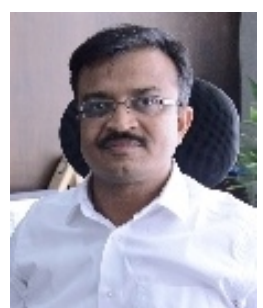

R. B. Jadeja is Professor \& DeanFaculty of Engineering at Marwadi Education Foundation's Group of Institutions. His area of interest includes control of power electronic converters, AC drives, Pulse Width Modulated power electronic converters, and Power Quality Conditioning Equipment. He is a Senior Member of IEEE and Member of IET.

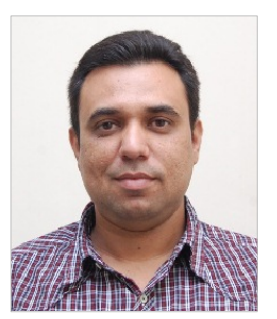

Praghnesh Bhatt did his $\mathrm{PhD}$ from $\mathrm{S}$ $\mathrm{V}$ National Institute of Technology, Surat, India in 2012. He is working as Professor in Department of Electrical Engineering at C S Patel Institute of Technology, Charusat, India. His areas of interests are Power System Analysis, Power system Dynamics and Stability, Grid integration of wind power generation, Power System Protection, Distributed Generation and power quality. 